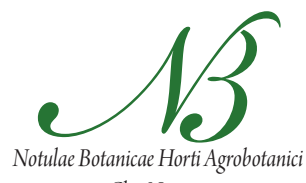

Cluj-Napoca

\title{
Interactive Effects of Sowing Date and Planting Density on Dry Matter Accumulation and Partitioning of Chicory
}

\author{
Hamid MADANI ${ }^{1}$, Christos DORDAS ${ }^{2}$, Ahad MADANI ${ }^{3 *}$ \\ Mohammad-AliMOTASHAREI',Shima FARRI ${ }^{1}$ \\ ${ }^{1}$ Islamic Azad University, Arak Branch, Arak, Iran \\ ${ }^{2}$ Aristotle University of Thessaloniki, School of Agriculture, Laboratory of Agronomy, Thessaloniki, Greece \\ ${ }^{3}$ Islamic Azad University, Gonabad Branch, Gonabad, Iran; madani_ahad@yahoo.com (*corresponding author)
}

\begin{abstract}
Chicory is considered one of the alternatives crops that can be used in crop rotation and contains many phytochemicals that can be used in medicine. In addition, lengthening the growing season by early sowing may increase root chicory yield potential, and thus increase its competitiveness with traditional crops. The objectives of the present study were to determine whether early sowing date risks can be decreased by higher sowing density and also to study the effect of sowing date and sowing density on dry matter accumulation and partitioning of chicory. Growing season did not affect any of the characteristics that were studied. Also plant density affected the flowers biomass, root biomass per plant and the respective yield together with the plant height and essence yield and total yield. The sowing date affected the leaf, flower and stem biomass on a plant basis. However, the interaction between plant density and sowing date affected the total biomass per plant, the flower biomass per plant, the root biomass per plant, the flower yield, the root yield and the essence yield. These results indicate that for higher production it is important to determine the right plant density and sowing date which can affect growth, dry matter accumulation and essence yield.
\end{abstract}

Keywords: biomass, chicory, essence yield, planting date, plant population

\section{Introduction}

Cultivation of chicory (Cichorium intybus) plants for the extraction of various phytochemicals and a number of pharmacological applications has received global attention in recent years (Bias and Ravishankar, 2001; Quanzhen and Jian, 2011). Cichorium intybus L, belongs to the Asteraceae family, forms flowering shoots and seeds after overwintering. For successful seed germination, chicory needs a minimum temperature of $21^{\circ} \mathrm{C}$, while for good plant growth it requires a moderate and uniform temperature, with the optimum at $18-24^{\circ} \mathrm{C}$ (Gianquinto and Pimpini, 1998). The chicory plant needs chilling for about 90 days to break dormancy and go from vegetative to reproductive phase (Dielen et al., 2005). When raised for roots, chicory requires a hot and humid climate; however, when raised for seeds, the crop is grown in regions with dry temperate climate (Bias and Ravishankar, 2001; Quanzhen and Jian, 2011).

The date of sowing is one of the most important factors affecting the performance of both chicory roots and seed crops (Schittenhelm, 2001). The seed for raising roots is sown in June in temperate climates and roots are ready by November. Roots are left as such under thick snow and replanted in March. After over wintering for 3-4 months at $3-8^{\circ} \mathrm{C}$, the roots can be replanted in March-April for the seed crop. The seed crop matures in August and is generally ready for harvesting 120-135 days after sowing. In hot and humid climates is sown in October-November (Bias and Ravishankar, 2001).

Root chicory yield may be further increased by better exploiting the growing season, i.e. by sowing in March instead of April or May (Schittenhelm, 2001). Westerdijk (1997) observed a linear decrease in root chicory yield for sowings after early April. Wilson et al. (1999) obtained similar chicory root yields when the crop was sown between 1 April and 1 May, but it was reduced by 30\% when it was sown in mid May. However, if planted early, the plants begin to flower early and tuber formation is adversely affected (Dielen $e t$ al., 2005). Low temperatures in spring can cause a number of plants to bolt in the year of sowing (Schittenhelm, 2001). Also Schittenhelm (2001) reported that bolters were almost absent at medium and late sowing, average bolting percentage at early sowing was $18.3 \%$ in the first year and $22.7 \%$ in the second year. Therefore, Baert and Van Bockstaele (1993) recommended root chicory should not be sown before mid April and it was found that bolters produced significantly lower root fresh weight and high proportion of above-ground parts. On the other hand, Schittenhelm (2001) found that increasing root chicory yield potential by early sowing is not limited by a lack of bolting-resistant cultivars, but by the 
184

risk of poor crop establishment due to unfavorable weather conditions.

Another cultural practice that can affect chicory yield is the sowing density. It was found that sowing distances of $40 \times 25 \mathrm{~cm}$ increased the yield by $29.6 \%$ compared with plants grown at spacing of $40 \times 35 \mathrm{~cm}$. In addition, there is a limited amount of information regarding the interaction between sowing density and sowing date on the growth and yield production of chicory (Rekowsca and JurgaSzlrmpo, 2011).

The objectives of present study were: to find whether early sowing date risks can be decreased by higher sowing density (1) and to study the effect of sowing date and sowing density on dry matter accumulation and partitioning of chicory (2).

\section{Materials and methods}

\section{Setup of the experiment}

The experiments were conducted at in two areas of Iran in Mashad and Arak during the growing seasons of 2009 and 2010, respectively. Arak is located at $34^{\circ} 6^{\prime} \mathrm{N}$ latitude, $49^{\circ} 46^{\prime} \mathrm{E}$ longitude, with an altitude of $1708 \mathrm{~m}$ above the sea level, with mean annual maximum and minimum daily air temperatures of $22.4^{\circ} \mathrm{C}$ (Month) and $8.2^{\circ} \mathrm{C}$ (Month), respectively. Mashad is located at $36^{\circ} 16^{\prime} \mathrm{N}$ latitude, $59^{\circ} 38^{\prime}$ E longitude, with an altitude of $999.2 \mathrm{~m}$ above the sea level, with mean annual maximum and minimum daily air temperatures of $21.1^{\circ} \mathrm{C}$ (Month) and $7.1^{\circ} \mathrm{C}$ (Month), respectively. These two regions have cold and dry climate (Tab. 1). The soil was sampled pre-planting at a depth of $30 \mathrm{~cm}$. The soil characteristics were determined according to methods detailed in Sparks et al. (1996) in the Shiraz Soil Testing Laboratory.

\section{Crop management and experimental design}

The experimental design was a factorial with three sowing dates and two sowing densities with four replications. Sowing dates were 15 March and 15 April in both growing seasons. The plant densities were 8,16 and 24 plants $\mathrm{m}^{-2}$. Plots were consisted of $6 \mathrm{~m}$ long rows spaced $0.5 \mathrm{~m}$ apart. The previous crop was wheat in both growing regions with a fallow period of 5-6 month. The land was cleaned and ploughed deep. Farmyard manure of well-rotted compost at the rate of $50 \mathrm{~kg} \mathrm{ha}^{-1}$, ploughed into the soil to a depth of $15-20 \mathrm{~cm}$ and leveled off. The field was prepared for sowing using a rotary harrow disk followed by a seedbed combination. The field was made into ridges and furrows, with a spacing of $50 \mathrm{~cm}$ between ridges and seeds were mixed with fine sand and sown in a depth of $3-5 \mathrm{~cm}$. The plots were over seeded threefold to avoid sub-optimal plant density due to poor emergence. Chicory seed was sown with a pneumatic seed drill. Irrigation was applied when cumulative pan evaporation values achieved $100 \mathrm{~mm}$ with the help of a water-contour installed near the field head.

Nitrogen as urea at levels of 50, 100 and $100 \mathrm{~kg} \mathrm{ha}^{-1}$ at the time of seed sowing, after thinning (20 days after germination) and at the root formation stage respectively was top-dressed. The $75 \mathrm{~kg} \mathrm{~h}^{-1}$ potassium and $100 \mathrm{~kg} \mathrm{~h}$ ${ }^{1}$ phosphorus were applied in the form of potassium sulfate and superphosphate respectively by placement $3-4 \mathrm{~cm}$ to the side of and below the seed line. Weeds were controlled by hand hoeing.

\section{Measurements}

When the roots attained optimum size, the plots were hand-harvested on 15 and 25 November in 2009 and 2010, respectively. At harvest, the plants were pulled up by hand and the leaves and elongated stems were cut off at their base. Only the four central rows, excluding the ter-

Tab. 1. Monthly means of maximum (Max), minimum (min) air temperatures and rainfall for the two areas where the experiments were conducted

\begin{tabular}{|c|c|c|c|c|c|c|c|c|}
\hline Month & $\operatorname{Max} .\left({ }^{\circ} \mathrm{C}\right)$ & Min. $\left({ }^{\circ} \mathrm{C}\right)$ & Hum. (\%) & Rainfall (mm) & $\operatorname{Max} .\left({ }^{\circ} \mathrm{C}\right)$ & Min. $\left({ }^{\circ} \mathrm{C}\right)$ & Hum. (\%) & Rainfall (mm) \\
\hline \multicolumn{5}{|c|}{ Arak } & \multicolumn{4}{|c|}{ Mashad } \\
\hline April & 22.3 & 7.4 & 42 & 19.5 & 20.8 & 8.2 & 62 & 46.3 \\
\hline May & 25.5 & 10.3 & 39 & 0 & 26.6 & 12.2 & 50 & 27.6 \\
\hline June & 31.6 & 15.0 & 26 & 0.1 & 32.3 & 16.2 & 37 & 4.2 \\
\hline July & 35.3 & 20.0 & 28 & 0.1 & 34.4 & 18.5 & 35 & 1.1 \\
\hline August & 35.5 & 18.6 & 24 & 1.6 & 33 & 16.2 & 34 & 0.8 \\
\hline September & 32.2 & 15.3 & 33 & 0.1 & 28.9 & 11.5 & 38 & 1.7 \\
\hline October & 27.5 & 10.6 & 35 & 5.5 & 22.3 & 6.1 & 50 & 8.6 \\
\hline November & 12.9 & 3.7 & 73 & 7.4 & 15.4 & 1.7 & 64 & 16.4 \\
\hline December & 13.1 & 2.6 & 68 & 78 & 9.7 & -1.9 & 73 & 24.7 \\
\hline January & 8.4 & -4.5 & 62 & 43 & 7.2 & -3.8 & 76 & 33 \\
\hline February & 9 & -1.1 & 69 & 19.6 & 9.2 & -2.1 & 73 & 35.2 \\
\hline March & 15.1 & 1 & 43 & 1.4 & 13.9 & 2.6 & 70 & 55.6 \\
\hline Total & & & & 176.3 & & & & 255.2 \\
\hline
\end{tabular}


minal plants from each end of the plot were used in determining the yield. The plot fresh yield of washed roots and aboveground plant parts were determined separately. Each plant part was dried at $105^{\circ} \mathrm{C}$ for $48 \mathrm{~h}$ to determine the dry matter. The $250 \mathrm{~g}$ samples of root were used to extract the essential oil using the "steam distillation" method.

\section{Statistical analysis}

All measured and derived data were analyzed separately for each year and combined across years by analysis of variance (GLM PROC) using the SAS computer software. Character means were separated by least significant differences (LSD, $p<0.05$ ) when sources of variation from the ANOVAs were significant $(p<0.05)$.

\section{Results}

The growing season did not affect any of the characteristics that were studied. In addition, the plant density (D) affected the flowers biomass per plant (FBPP), root biomass per plant (RBPP), leaf yield (LY), flower yield (FY), root yield (RY), total yield (TY), plant height $(\mathrm{PH})$, and essence yield (EY) (Tab. 2). The sowing date (S) affected leaves biomass per plant (LBPP), flowers biomass per plant (FBPP), and stem biomass per plant (SBPP). The interaction between $\mathrm{Y}$ and $\mathrm{D}, \mathrm{Y}$ and $\mathrm{S}$ and the three way interaction $\mathrm{Y}, \mathrm{D}$ and $\mathrm{S}$ did not affect any of the characteristics that were studied. The interaction between sowing density and sowing date (DS) affected TBPP, FBPP, RBPP, FY, $\mathrm{RY}$, and EY. Therefore only the significant interactions are discussed and the main effects are presented.

Flowers biomass per plant (FBPP), (RBPP), leaf yield (LY), flower yield (FY), root yield (RY), total yield (TY), and essence yield (EY) were higher at the 8 plants $\mathrm{m}^{-2}$ treatment compared with the other two treatments (16 and 24 plant $\mathrm{m}^{-2}$ ) (Tab. 3 and Tab. 4). In addition, higher FY was found at the 24 plants $\mathrm{m}^{-2}$. LBPP and SBPP were higher at the S2 (15 of April) than the S1 (15 of March). Also FBPP was higher at the early sowing date (S1) than the late sowing date (S2) treatment. TBPP, FBPP, RBPP, FY and RY were higher at the D1S1 than the D2S2 treatment. Regarding the D2S1 was higher at the FBPP, RBPP, FY and EY compared with the D2S2. In addition D3S1 was lower at the TBPP, FBPP, RBPP, RY compared with the D3S2.

\section{Discussion}

Early sowing did not affect the yield but only affected the yield components such as LBPP, FBPP, and LY. Early sowing in many cases is preferred as it has the potential to increase considerably yield especially in Mediterranean climates but can enhance the risk of bolting (Baert, 1997). However, in the present study bolting didn't occur in both trial years thanks to the mild spring in those years. In addition, bolting resistance can be increased by breeding because of the high heritability of this feature (Baert, 1993). A fast early leaf growth is desirable as it can further increase yield (Meijer and Matthijsen, 1993). Also total essence content depends mainly on the cultivar that was used and was not influenced by the sowing date and planting density.

Crop physiologists and breeders have stressed the importance of rapid early growth and cold tolerance for early sowing to improve chicory yield (Baert, 1993; Meijer and Mathijssen, 1992). However, this diversity might not only reflect genetic differences as Wiebe (1989) found that chicory seed partly vernalise during seed development if the mother plant is exposed to low temperature.

In addition, chicory exhibits a slow leaf growth at low temperature (Meijer and Mathijssen, 1992). The amount of extra radiation intercepted at early sowing thus depends on how much emergence and early growth are affected by temperatures after sowings in March, which are less favorable than those in April or early May as it was found in other studies.

The total yield that was found in this study, considering the values reported in the literature (Douglas and Poll,

Tab. 2. Analysis of variance of the different characteristics in separate and combined analysis of two growing seasons (regions) that were determined in this study and were affected by growing season (regions) (Y), plant density (D) and sowing date (S) and their interactions

\begin{tabular}{cccccccccccccccc}
\hline S.O.V & DF & TBPP & LBPP & FBPP & RBPP & SBPP & LY & FY & RY & PH & SD & NB & EY & TY & EP \\
\hline Growing season(Y) & 1 & NS & NS & NS & NS & NS & NS & NS & NS & NS & NS & NS & NS & NS & NS \\
Plant density (D) & 2 & NS & NS & ${ }^{* *}$ & ${ }^{* *}$ & NS & ${ }^{*}$ & ${ }^{* *}$ & ${ }^{* *}$ & ${ }^{*}$ & NS & NS & ${ }^{* *}$ & ${ }^{* *}$ & NS \\
\hline Sowing date (S) & 1 & NS & ${ }^{*}$ & ${ }^{* *}$ & NS & ${ }^{*}$ & NS & NS & NS & NS & NS & NS & NS & NS & NS \\
\hline YS & 2 & NS & NS & NS & NS & NS & NS & NS & NS & NS & NS & NS & NS & NS & NS \\
YV & 1 & NS & NS & NS & NS & NS & NS & NS & NS & NS & NS & NS & NS & NS & NS \\
SV & 2 & ${ }^{* *}$ & NS & ${ }^{* *}$ & ${ }^{*}$ & NS & NS & ${ }^{* *}$ & ${ }^{*}$ & NS & NS & NS & $*$ & NS & NS \\
YSV & 2 & NS & NS & NS & NS & NS & NS & NS & NS & NS & NS & NS & NS & NS & NS \\
\hline
\end{tabular}

TBPP: total biomass per plant; LBPP: leaves biomass per plant; FBPP: flowers biomass per plant; RBPP: root biomass per plant; SBPP: stem biomass per plant; LY: leaves yield: FY: flower yield; RY: root yield: TY: total yield; PH: plant height; SD: stem diameter; NB: number of branches; EY: essence yield; EP :essence percentage. Y: year effect; D: Plant density; S: sowing date; YD, YS, DS, YDS represent interaction terms between the different factors that was tested in this study ${ }^{* *} p<0.01 ;{ }^{*} p<0.05$; ns $\mathrm{P}>0.05$ 
186

Tab. 3. Mean values of total biomass per plant (TBPP), leaves biomass per plant (LBPP), flowers biomass per plant (FBPP), root biomass per plant (RBPP), stem biomass per plant (SBPP), leaves yield (LY), flower yield (FY), root yield (RY), total yield (TY), plant height $(\mathrm{PH})$, stem diameter $(\mathrm{SD})$, and number of branches (NB) of two growing seasons (regions)

\begin{tabular}{|c|c|c|c|c|c|c|c|c|}
\hline S.O.V & ТВPP (g) & $\operatorname{LBPP}(\mathrm{g})$ & $\operatorname{FBPP}(\mathrm{g})$ & $\operatorname{RBPP}(\mathrm{g})$ & $\operatorname{SBPP}(\mathrm{g})$ & $\mathrm{PH}(\mathrm{cm})$ & $\mathrm{SD}(\mathrm{cm})$ & $\mathrm{NB}$ \\
\hline D1 & 61.9 & 23.4 & 14.8 & 7.6 & 15.8 & 91.5 & 9.6 & 11.9 \\
\hline D2 & 56.5 & 22.8 & 12.7 & 4.8 & 14.8 & 100.6 & 9.3 & 11.5 \\
\hline D3 & 59.5 & 26.9 & 9.3 & 6.6 & 15.9 & 86.3 & 8.8 & 11.6 \\
\hline LSD & 8.76 & 4.7 & 1.8 & 1.5 & 1.76 & 10.7 & 1.03 & 2.67 \\
\hline S1 & 59.2 & 22.6 & 15.2 & 6.4 & 14.8 & 92.8 & 8.9 & 11.5 \\
\hline S2 & 59.4 & 26.1 & 9.4 & 6.3 & 16.2 & 92.7 & 9.6 & 11.8 \\
\hline LSD & 7.15 & 3.4 & 1.4 & 1.2 & 1.4 & 8.78 & 0.84 & 2.18 \\
\hline D1S1 & 67.5 & 24.1 & 19.9 & 8.8 & 14.6 & 90.1 & 9.3 & 12.8 \\
\hline D1S2 & 56.4 & 22.7 & 9.9 & 6.3 & 17.1 & 92.6 & 9.9 & 11.0 \\
\hline LSD & 11.7 & 4.72 & 2.4 & 2.3 & 2.73 & 13.8 & 1.06 & 1.51 \\
\hline $\mathrm{D} 2 \mathrm{~S} 1$ & 59.8 & 19.5 & 16.7 & 5.1 & 15.1 & 104.8 & 9.0 & 10.8 \\
\hline $\mathrm{D} 2 \mathrm{~S} 2$ & 53.1 & 26.0 & 8.7 & 4.6 & 14.5 & 96.3 & 9.6 & 12.1 \\
\hline LSD & 7.7 & 6.49 & 1.7 & 1.2 & 1.49 & 15.9 & 1.03 & 2.89 \\
\hline D3S1 & 50.3 & 24.1 & 8.9 & 5.3 & 14.8 & 83.6 & 8.4 & 10.8 \\
\hline D3S2 & 68.7 & 29.7 & 9.6 & 7.9 & 17.1 & 88.9 & 9.4 & 12.1 \\
\hline LSD & 12.8 & 4.40 & 1.4 & 1.6 & 2.74 & 13.5 & 1.33 & 4.01 \\
\hline
\end{tabular}

Tab. 4. Mean values of leaf yield (LY), flower yield (FY), root yield (RY), total yield (TY), plant height (PH), stem diameter (SD), number of branches (NB), essence percentage (EP) and essence yield (EY) of two growing seasons (regions)

\begin{tabular}{ccccccc}
\hline S.O.V & LY & FY & RY & EY & TY & EP (\%) \\
\hline D1 & 5709 & 1277 & 363 & 388 & 8872 & 0.10 \\
D2 & 2756 & 1476 & 239 & 374 & 5493 & 0.15 \\
D3 & 1302 & 447 & 105 & 164 & 1919 & 0.16 \\
\hline LSD & 415 & 83.7 & 29.7 & 68.9 & 542 & 0.06 \\
\hline S1 & 3161 & 1063 & 232 & 335 & 5347 & 0.14 \\
\hline S2 & 3350 & 1071 & 239 & 282 & 5498 & 0.12 \\
LSD & 338 & 68.3 & 24.3 & 56.3 & 444 & 0.05 \\
\hline D1S1 & 5512 & 1077 & 382 & 402 & 8295 & 0.10 \\
D1S2 & 5906 & 1477 & 345 & 374 & 8809 & 0.11 \\
\hline LSD & 806 & 118 & 59.7 & 88 & 1140 & 0.04 \\
\hline D2S1 & 2765 & 1645 & 229 & 451 & 5427 & 0.18 \\
\hline D2S2 & 2748 & 1307 & 249 & 297 & 5121 & 0.12 \\
LSD & 659 & 113 & 36.3 & 93.4 & 969 & 0.07 \\
\hline D3S1 & 1206 & 467 & 85 & 154 & 2074 & 0.18 \\
D3S2 & 1397 & 428 & 124 & 175 & 2299 & 0.14 \\
\hline LSD & 145 & 69 & 22.2 & 37.7 & 283 & 0.06 \\
\hline
\end{tabular}

1986; Frese and Dambroth, 1987; Voltolina, 1994) seems to be quite low: from 1919-8872 $\mathrm{t} \mathrm{ha}^{-1}$ depending on sowing date. This low yield compared with other studies can be because of the dry Mediterranean climate or that the cultivar that was used had much lower yield potential (Amaducci and Pritoni, 1998)

Plant density affected more the dry matter yield than the sowing date and the highest yield was found at the 8 plants $\mathrm{m}^{-2}$ density. The interaction between plant density and sowing date affected the essence yield and was higher at the D2S1 treatment compared with the other treatments. In addition, the interaction between sowing date and plant density was not determined before and this study provides some new insights of this interaction and points out the need for careful management practices that can affect yield, biomass accumulation and partitioning and also quality.

\section{Conclusions}

Early sowing together with the appropriate plant density may considerably increase total yield. Therefore, the proper cultural techniques are important for higher production of chicory. Chicory has the potential to become a high-quality and high-yielding arable crop and can be used in crop rotation over a wide range of conditions. Intensive breeding may solve part of the phytotechnical problems, e.g. inulin yield, bolting resistance, early growth. However, to date, little is known about the effects of cultivation techniques (sowing data and plant density) on the carbohydrate composition of the chicory root. Further research on cultivation, crop management techniques and their interaction will be useful for developing optimum management practices for the production of chicory.

\section{References}

Amaducci S, Pritoni G (1998). Effect of harvest date and cultivar on Cichorium intybus yield components in north Italy. Ind Crop Prod 7:345-349.

Baert JRA, Van Bockstaele E (1993). Cultivation and breeding of root chicory for inulin production. Ind Crop Prod 1:229234.

Baert J (1993). The potential of inulin chicory as an alternative high income crop, 119-127 p. In: The Production and Impact of Specialist Minor Crops in the Rural Community. Proc of an EC workshop, Brussels. 
Baert JRA (1997). The effect of sowing and harvest date and cultivar on inulin yield and composition of chicory (Cichorium intybus L) roots. Ind Crop Prod 6:195-199.

Bias HP, Ravishankar GA (2001). Cichorium intybus L-cultivation, processing, utility, value addition and biotechnology, with an emphasis on current status and future prospects. J Sci Food Agric 81:467-484.

Dielen V, Notte C, Lutts S, Debavelaerea V, Van Herck JC, Kinet JM (2005). Bolting control by low temperatures in root chicory (Cichorium intybus var. sativum). Field Crop Res 94:76-85.

Douglas J, Poll S (1986). A preliminary assessment of chicory (Cichorium intybus) as an energy crop. NZ J Exper Agric 14:223-225.

Frese L, Dambroth M (1987). Research on the genetic resources of inulin-containing chicory (Cithorium intybus). Plant Breed 99:308-317.

Gianquinto G, Pimpini F (1998). The influence of temperature on growth, bolting and yield of chicory. J Hort Sci 64:687695.

Meijer WJM, Matthijsen EWJM (1992). Experimental and simulated production of inulin by chicory and Jerusalem artichoke. Ind Crop Prod 1:175-183.

Quanzhen W, Jian C (2011). Perspectives and utilization technologies of chicory(Cichorium intybus L.): A review. Afr J of Biotechnol 10:1966-1977.
Rekowska E, Jurga-Szlempo B (2011). Influence of growing date and plant density on the yield of Endive. Acta Sci Pol Horturum Cultus 10(1):13-21.

Schittenhelm S (2001). Effect of sowing date on the performance of root chicory. Europ J Agron 15:209-220.

Sparks DL, Page AL, Helmke PA, Loeppert RH, Soltanpour PN, Tabatabai MA, Johnson CT, Sumner ME (1996). Methods of Soil Analysis: Part 3-Chemical Methods Agron. Monogr. 9. $2^{\text {nd }}$ Ed. ASA and SSSA, Madison, WI, USA.

Voltolina G (1994). Valutazione di specie diverse per la produzione di fruttosio ed inulina. L'informatore Agrario 33:25-32.

Westerdijk CE (1997). Chicory for inulin productionResults of 4 years of crop research, 25-28 p. In: Fuchs A, Schittenhelm S, Frese L (Eds.). Proc of the Sixth Seminar on Inulin, Braunschweig, Germany. Carbohydrate Research Foundation-European Fructan Association, The Hague, The Netherlands.

Wiebe HJ (1989). Effects of low temperature during seed development on the mother plant on bolting of vegetable crops. Acta Hortic 253:25-30.

Wilson R, Smith J, Yonts D, Hibberd C (1999). Chicory production in Nebraska (USA) for inulin processing, 1324 p. In: Fuchs A, van Laere A (Eds.). Proc of the Seventh Seminar on Inulin, Leuven, Belgium. European Fructan Association, Stuttgart, Germany. 